\title{
On How to Make Use of Tax Policies to Realize More Equitable Distribution of Income
}

\author{
Zhang Jue \\ International School of Beijing University of Posts and Telecommunications \\ zhangjue1992@sina.com
}

\begin{abstract}
Through analyzing the present status of increasingly intensified income distribution gap and summarizing the effects upon income distribution by tax policy and existing problems, the paper puts forward some principles and advices on tax policy reform, to realize more equitable distribution of income and create more fair and harmonious society step by step.

Index Terms - Tax policy; Income Distribution; Fair and Harmony
\end{abstract}

\section{Present Status of Income Distribution in China}

$\boldsymbol{A}$ - According to urban and rural per capita income ratio, the ratio is approximately $2: 1$ in the early days of reform and opening-up, $2.72: 1$ in $1995,2.92: 1$ in 2001 and $3.22: 1$ in 2005. Although the data drops from $3.33: 1$ in 2007 to $3.31: 1$ in 2008 , the absolute gap has topped ten thousand yuan for the first time. a), In recent years, the ratio is maintained at 3.21:1, China has implemented many agricultural policies though. Taking into the considerations of welfare housing, transportation, health care and other public services, we can see the urban and rural income ratio in China is far more than the apparent $3: 1$.

B - According to Gini coefficient, the income gap is increasingly enlarged. In 1978, Gini coefficient in China is basically maintained between 0.2 and 0.24 , yet rising to 0.34 in 1990, 0.37 in 1995 and more than 0.44 in 2000. To conservatively estimate, now Gini coefficient in China is at least 0.44 and this is greatly serious.

$\boldsymbol{C}$ - From the angle of regional differences, the difference between east and middle-west is the most obvious. Since reform and opening-up in 1978, per capita GDP in every region has largely increased, but the same as the gaps among these regions. In 1980, the ratios among east, middle and west are correspondingly $1.8: 1.18: 1$, but increasing to 1.9 $: 1.17: 1$ in $1990,2.63: 1.26: 1$ in 2002 and $2: 1: 0.86$ in 2008. Although we have carried out the strategy of western development and the rise of the middle and the GDP increasing speed of middle-west has exceeded that of the east in a time, the difference between the regions is still very obvious due to the poor base of middle-east regions.

$\boldsymbol{D}$ - From the angle of industry, the highest industry and lowest industry wage ratio is $1.38: 1$. In 2009, the highest and lowest industry average wage ratio is $4.68: 1$, but taking the extrawage income and welfare into consideration, we can find that the real income ratio may rise to 5-10. While the wage of some employers in monopoly industries such as power industry is much higher than social average wage. The phenomenon is widely criticized in society.

\section{The Existing Problems in the Process of Adjusting Income Distribution Through Tax}

In recent years, the increasing range of tax revenue has exceeded that of GDP for years running, but from the income distribution situation reflected by Gini coefficient, the widening trend of the gap between rich and poor has not been curbed. On the contrary, as the china fiscal revenue-GDP ratio increases, Gini coefficient is increasing. The phenomenon caused results manly from the tax structure of our country. Different types of taxes have different functions in regulating income distribution, such as personal income tax and other direct taxes, due to the difficulty of passing on tax burden and the adaption of progressive tax rate, have much more powerful regulating function than value-added tax and other indirect taxes. Generally speaking, personal income tax, property tax, consumption tax and tariff have a stronger function in regulating income distribution compared to value-added tax and business tax. But the tax revenue in China is mainly from commodity turnover taxes among which indirect taxes such as value-added tax account for the main part. Thus the function of tax revenue in regulating income distribution is relatively weak. The rapid tax revenue increase in recent years is mainly attributed to the indirect taxes which have weaker functions in regulating income distribution such as value-added tax, business tax, stamp duty on securities transaction and so on. Therefore, the optimization of income distribution doesn't accompany the rise of tax revenue. Take the data in 2007 as an example, commodity turnover taxes which have a weaker function in regulating income distribution accounted for over $60 \%$ of the whole tax revenue, but only $15 \%$ or so as to personal income tax, consumption tax, property tax and others which have s strong function in regulating income distribution.

In our tax system, personal income tax, consumption tax, property tax and some other taxes have stronger functions in regulating income. However except their small proportion in tax revenue, there are also many shortcomings in the setting of tax system elements. So the regulating functions are not fully expressed.

\footnotetext{
${ }^{*}$ This article is funded by the innovation fund of Beijing University of Posts and Telecommunications.
} 


\section{Principles of Tax Policy Reform}

$\boldsymbol{A}$ - Optimize tax system and tax regulation system. Building the dual-subject mode in which cargos and service tax, income tax share the dominant role, taking personal income tax as the main part and complementing the social security tax and estate duty tax regulating system can help to effectively take use of progressive role of tax burden, reflect the principle of paying tax according to personal abilities, avoid the enlargement of income gap and play an important role in realizing equitable income distribution. Now per capita GDP in China is 3711 dollars, which has formed the basic condition for tax reform.

$\boldsymbol{B} \cdot$ Reform types of taxes and perform tax regulation function. As to personal income tax, building personal income tax system mode with the combination of comprehensiveness and classification, scientific source-control procedures and rigorous audit and penalty system play an irreplaceable role in narrowing income gap and encouraging equitable distribution, as well as help to realize the ultimate goal of personal income tax law to "adjust the income gap and improve the overall welfare of society through the financial transfer payment". For value-added tax, reducing the tax ratio on necessities can lower the price of necessities and reduce the impact upon lowincome group thus reduce their burden. As for social security tax, implementing "fee to tax" can improve the support capabilities of social security fund and fully perform its function of Risk diversification and transfer payments. And for property tax, increasing high-end residential tax and suspending common housing tax can reduce invalid charges in real estate industry and perform the function of regulating housing price through tax.

$C$ - Perform the supporting function of tax and increase the income of the low-income group. Strengthening the tax policy support upon agriculture, encouraging the professionalization of agriculture production and building modern agriculture market system provide a main way to largely increase the added value of agricultural products then to increase farmers' income. The methods like optimizing tax regulating function, improving the tax environment for small and medium enterprises (SEMs) and supporting the strong growth of SEMs play an important role in increasing employment and people's income. Reducing venture threshold and the entrepreneurial risk through tax incentives, increasing the enthusiasm of independent venture and especially encouraging the reemployed group and difficult families to venture are of great significance in increasing employment, increasing people's income, narrowing income gap and promoting social harmony and stability.

D - Build tax source-control system and strengthen tax collection measures. Strengthening the efforts of punishing tax evasion through the tax source-control system is of great help to supervise the tax sources of personal incomes especially those high-income groups, to make up the loopholes of the tax collection, to improve tax compliance level, and not only to perform tax regulation function to realize equitable income distribution, but also to realize the government objective of "protecting lawful incomes, regulating excessively high incomes and banning illegal income".

$\boldsymbol{E}$ - Continue to intensify policy support on middle-west regions. Prolonging the period of tax incentives and intensifying tax incentives through increasing the local share proportion of shared taxes in middle-west regions can effectively improve the local financing ability, financial capacity and macro-control ability to improve people's livelihood, and play an important role in narrowing regional income gap, accelerating equitable income and realizing coordinated development between east and Midwest. According to the specific circumstances of Midwest, it is considerable to improve resource tax rate, widen the range of resource tax collection, increase ways of tax incentives and propose preferential measures in ecological resettlement and resource depletion regions.

\section{Establish the target of justly regulating income distribution and optimize personal income tax system}

$\boldsymbol{A}$ - Formulate reasonable deduction standard of personal income tax. Since reform and opening-up, many reforms in livelihood have been increasingly inclined to industrialization and marketization. And people's expenses in livelihood fields has been increased, so contents such as household maintenance, tending burden pension insurance, medical insurance, unemployment insurance, housing insurance should be included in the personal income deduction. It is recommended that we must hurry to standardize the labor income deduction and distinguish between costs and livelihood expenses. As for the costs, it must be the normal costs for obtaining service income like travel expenses, meal subsidies, social insurance, etc. Costs unrelated to the service acquirement are not normal expenses and can't be included in costs deduction. For livelihood expenses, we should take a comprehensive consideration of health care, education, housing, unemployment, pension and others involved in income distribution reform, to strive to fully take into account the individual differences of different taxpayers and to achieve tax fairness.

$\boldsymbol{B}$ - Regularly adjust personal income tax deduction standards. Personal income tax deduction standards must be regulated correspondingly as people's income rise year by year. According to the situation of inflation, we can adapt the indexation of personal income tax deduction standard and allow the central to formulate expense deduction benchmark and empower the local some float right of expense deduction referring to local per capita GDP and price level.

$C$ - Adapt excess progressive form in tax rate design. Regulating income gap and realizing equitable distribution is the target of the personal income tax reform. As for the personal income tax impose through service income, we should adapt excess progressive rate, lower the level of income tax rate and enlarge the gap between different levels and lower 
the highest marginal tax rate so as to make people who have large affordability bear more tax burden and those who have small affordability bear less tax burden. Besides, we can consider to lowering the income tax rate of people who are engaged in transportation, construction, culture and sports and service industries to reduce their tax burdens and increase the proportion of labor income in the entire national income distribution.

D - Keep the same type of personal income taxes consistent. Now the temporary workers who are long-term employed but didn't sign labor contract have much heavier tax burden than fixed labors who have signed labor contract. This is because it adapts the deduction standards and the tax rate according to labor income when we count their taxes. Since temporary workers are not insured "three insurances and one fund", we can't do the deduction from the money. On the contrary, for the fixed workers who are insured "three insurances and one fund", we adapt the deduction standard according to their salaries. Obviously, provided they have the same income, temporary workers have much higher taxes. Therefore, we recommend that government should equalize the two deduction standards and rates, follow the principle of substance over form and realize tax fairness using the same tax calculation methods.

\section{Optimize types of taxes like consumption tax and property tax, and intensify the efforts to regulate income distribution}

$\boldsymbol{A}$ - For consumption tax, on the one hand, we should timely regulate the range of tax collection according to the changes of economy situations. When enlarge the range of tax collection, we should consider not only luxury products items such as high fashion, high-end entertainment facilities but also some consumption behavior such as sauna bath, nightclubs and amusement. On the other hand, we should regulate the taxation links of consumption tax. Now we mainly impose consumption tax on production link, which will easily cause tax evasion. For example, some companies usually build a sales company, and they firstly sell the products to the sales company with a low price then the sales company sells the products to the market with normal price. This behavior not only encourages the company to avoid the tax but also reduces the regulation function.
$\boldsymbol{B}$ - For property tax, on the one hand, we should enlarge the range of tax collection, which includes operating real estate, rental property and also owner-occupied real estate. On the other hand, we should formulate the tax base and tax rate according to the value and actual use of the property. For the house only for the function of meeting life needs, we adapt low tax rate or free tax rate. But for the house that exceeds the housing standard, we adapt higher tax rate for the exceeded area. This will help to narrow the gap between rich and poor. Besides, we could choose the right time to carry out social security tax, estate duty, gift tax and so on, which have o strong distribution function. With the development of our economy, we have equipped the conditions to impose these taxes.

\section{Conclusion}

All in all, since the tax reform involves the interests of everyone, we should consider not only the continuity, fairness, purpose and operability of the policy but also the reform direction of justly regulating the income distribution. When formulating carrying out the detailed tax policy, we can adapt pilot implementation according to types of tax, different region, and different phases, and gradually extend them to fully express the function of scientific regulation and to realize equitable income distribution step by step. We should hold to scientific concepts of development, work hard to build income tax regulation system in which efficiency and fairness are balanced to comprehensively and justly regulate the present situation of income distribution, to comprehensively improve the incomes of low-income group, to narrow the income gap, to reverse the trend of polarization of income distribution and the enlargement of the gap between rich and poor, to truly realize the goal that the fruits of economic development are shared by the people, and to promote political and economic stability and social harmony.

\section{References}

(1) JiangJiayi Suggestion on Improving Chinese Personal Income Tax System, China's Finance, 2010, 02

(2) GaoPeiyong Prospect of Personal Income Tax Reform, China's Finance, 2009, 11

(3) TanYun Discussion on Internal Adjustment System of Tax Revenue on Income Distribution, Journal of Finance and Economics, 2009, 02 